\title{
Eustacio y el Proemio de sus Comentarios a la llíada
}

\author{
LUCIA ADRIANA LIÑARES \\ Universidad de Buenos Aires
}

\begin{abstract}
RESUMO: No Prólogo de seus Comentários à llíada, Eustácio faz referência aos valores essenciais da poesía homérica, e, também, a algumas questões abordadas pela crítica. O presente trabalho procura delimitar e definir a orientação interpretativa que manifesta o prólogo de Eustácio, a partir da análise das referências que o texto oferece.
\end{abstract}

PALAVRAS-CHAVE: Discurso; referência; pessoa; llíada; Eustácio; escolios e comentários; crítica.

\section{Introducción}

El presente trabajo forma parte de un proyecto de investigación más amplio sobre el estudio de la transmisión e interpretación de los poemas homéricos. El material proporcionado por la erudición alejandrina actúa como elemento mediador entre los poemas y el texto de los comentaristas posteriores. Los antiguos comentarios jerarquizan varios mecanismos de acceso al discurso épico, entre los que se destaca una tendencia apologética, representada por obras de exégesis, en las cuales varios estratos recubren los logros de los alejandrinos; entre los exponentes de esta tendencia, figuran los comentarios del Arzobispo Eustacio de Tesalónica a la Ilíada y la Odisea, del siglo XII ${ }^{1}$. En estos comentarios se incorpora la tradición gramatical antigua, en el marco de un texto complejo ${ }^{2}$. Defiende la obra homérica con una férrea voluntad pedagógica; se aleja así de la metodología alejandrina. La crítica distingue el modo alegórico temprano de interpretación y la penetración psicológica, avalada por profundos conocimientos de retórica y estilística, que caracteriza las observaciones de Eustacio ${ }^{3}$.

En el Proemio de sus Comentarios a la Ilíada, organiza una introducción en la que hace referencia a los valores esenciales de la poesía homérica, como así también a algunas cuestiones que han preocupado a los críticos. Este texto introductorio proporciona información para interpretar el criterio metodológico de Eustacio, en tanto describe el marco formal de su realización discursiva: se presenta como enunciador responsable, e inscribe frente a él la presencia de los eventuales destinatarios. Además, establece una particular relación referencial con su objeto de estudio ${ }^{4}$. 


\section{Objetivos}

El presente trabajo procura delimitar y definir los lineamientos principales que han de orientar la exégesis de Eustacio, a partir de la interpretación de los elementos que el texto introductorio proporciona.

\section{Corpus}

Este Proemio consta de cuatro párrafos de diversa extensión: en el primero, plantea un elogio de la poesía homérica en general haciendo referencia al hechizo inevitable que produce. A continuación, una vez que jerarquiza la poesía de Homero por su excelencia, enumera todas las clases de sabios que se vincularon o pueden vincularse con el poeta, como los filósofos, retóricos, gramáticos, poetas, geógrafos, etc. También habla de las múltiples bondades y virtudes de la poesía épica; respecto de los mitos se extiende más: reflexiona sobre el modo en que Homero los entreteje con su arte, y a través de ellos seduce a los sabios, aún a aquellos que lo rechazan, por inclinarse hacia lo verdadero. Concluye interrumpiendo su reflexión, y señalando que no es éste su propósito, al cual hará referencia más adelante.

En el extenso segundo párrafo, Eustacio desarrolla el planteo del objetivo de su trabajo, al tiempo que especifica al receptor de su obra, y también al eventual crítico: señala que su comentario está dirigido al joven estudiante (no al hombre docto); para éste, las cosas provechosas de la poesía homérica serán elegidas y ordenadas (pensamientos, métodos, expresiones, sentencias, historias, mitos). Puntualiza el modo en que ha de ordenar metódicamente el material. Una vez que presenta en forma global su criterio, el cual justifica frente a posibles críticas, especifica con más precisión que su tarea se ha de desarrollar en estrecha relación con los estudiosos anteriores (ól $\pi \alpha \lambda \alpha$ loí). Resume y discute tres modos de interpretación de la poesía homérica: el alegórico, el crítico (entendido como "textual": jerarquiza a Aristarco como el principal exponente), y el representado por los " $\alpha \kappa \rho \imath \beta \varepsilon$ $\sigma \tau \varepsilon \rho \circ$ ”", los "más precisos y minuciosos", los cuales examinan la invención y la plausividad (en dicha invención) de los mitos e historias, y una vez analizados, los consideran alegóricamente, de acuerdo con las leyes que organizan las tres áreas de la filosofía': $\phi v ́$

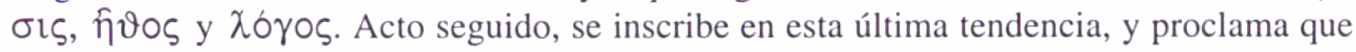
trabajará de esta manera con la apoyatura de la crítica anterior. Finaliza el parágrafo reconociendo que también su obra presentará argumentos en disidencia.

El tercer párrafo, el más breve, consiste en una reflexión sobre el concepto del

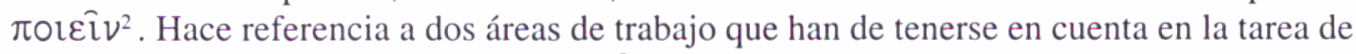
investigación: se debe examinar el $\pi$ oleî $\nu$, su etimología y su significado. Además, y en relación con esto, se ha de buscar y definir el aspecto y características de la epopeya. Finaliza con un elogio a Homero como el principio generaldo de la virtud poética, y guía para todos los poetas. Cierra el párrafo con una nueva alusión a su interés de no desviarse del propósito de la obra.

En el último párrafo, Eustacio advierte que no se ha de extender en el tema del origen de Homero. Brinda algunos datos y fuentes sobre las ciudades que se disputan su nacimiento, sobre poetas anteriores (como Museo, Orfeo). También da su opinión sobre la etimología de O $\mathrm{H} \eta \mathrm{pos}_{\text {; }}$ cita otros poemas del mismo autor, y recuerda que algunos críticos analizaron y compararon la Iliada y la Odisea, en tanto que otros estudiaron la disputa con 
Hesíodo. Finalmente, hace referencia al tema de las obras. Puntualiza que su propósito no está relacionado con lo histórico sino con lo discursivo, y en virtud de esta aclaración, evalúa a la Ilíada como $\alpha \nu \delta \rho \omega ́ \delta \eta \varsigma, \sigma \varepsilon \mu \nu \circ \tau \varepsilon \rho \alpha$ y

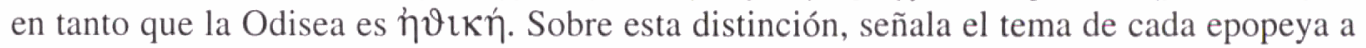

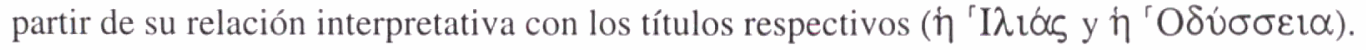
Concluye el proemio con el mismo estilo conclusivo de cada parágrafo: interrumpe estos comentarios generales que ha venido presentando, para echar mano a su verdadero propósito, que es, como ya se dijo, el análisis discursivo.

\section{Desarrollo}

4.1. Luego de este comentario general, por el cual se ha procurado describir al Proemio como un todo, la presente comunicación pasa a la cuestión específica de interpretar su organización discursiva mediante el análisis de las referencias personales ${ }^{7}$, involucradas en tres instancias básicas de toda investigación:

a) la fundamentación teórica

b) los objetivos

c) los métodos ${ }^{8}$.

a) El planteo de Eustacio se funda sobre una cuidadosa reflexión de la crítica homérica anterior, designada en forma genérica ól $\pi \alpha \lambda \alpha$ loí, o por medio de la especificación de referencias particulares (como Aristarco, Eliano, Heródoto, el poeta Píndaro y el trágico Eurípides); también algunas formas verbales apuntan a fuentes no definidas $(\phi \alpha \sigma l(\nu), \lambda \dot{\varepsilon}$ $\gamma \varepsilon \tau \propto l$, etc.) que sirven de fundamento para ciertas interpretaciones.

$\mathbf{b}_{1}$ ) El propósito ( $\sigma \kappa \circ \pi \delta_{\zeta}$ ) de su obra es el análisis del discurso épico, de acuerdo con la exposición breve y variada de una selección rigurosa de temas y métodos. La referencia a este $\sigma \kappa o \pi \delta \zeta$ organiza la presentación y cierre de cada parágrafo, como por ejemplo ${ }^{9}$ :

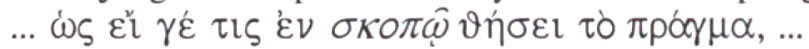
$\mu \varepsilon \vartheta \alpha$.

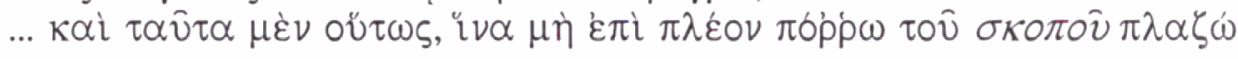
$\pi \varepsilon \rho \tau \tau \tau \alpha, \ldots$

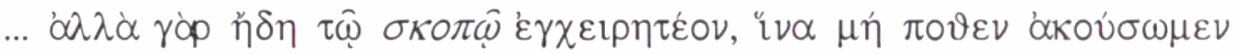

$\mathbf{b}_{2}$ ) En la expresión de los objetivos se privilegia la figura del sujeto enunciador, quien se presenta con las siguientes formas:

1) 1ra. pers. plural (con sentido de "modestia" 10 ; excluye al destinatario en la

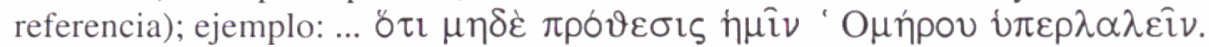

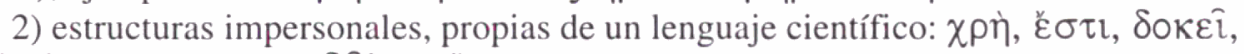
$\delta$ $v \alpha \tau o ́ v ~ ' \varepsilon \sigma \tau \imath+$ infinitivo; $\delta \hat{\eta} \lambda o v(o ̋ \tau)$.

3) adjetivos verbales (en construcción impersonal): ‘ $\alpha \alpha \lambda \varepsilon \kappa \tau \varepsilon \circ \nu, \pi \rho \circ \gamma \rho \alpha \pi \tau \varepsilon \circ \nu$,

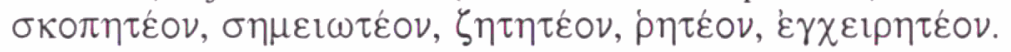

4) lra. pers. singular de verbos declarativos y de opinión, para formular una "distancia objetivizante", dado que le permite a Eustacio desdoblarse, al reflexionar sobre su propio enunciado, y de este modo, objetivarse" : ó $\mu \alpha \imath$, oí $\delta \alpha$.

5) referencias indirectas a sí mismo, por medio de expresiones que designan su

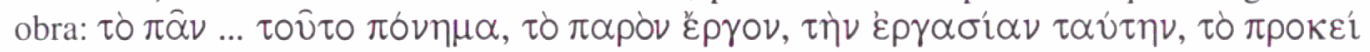

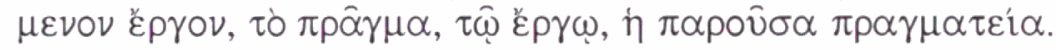

c) su presencia metodológica se incorpora al estudio de los poemas homéricos siguiendo una tradición interpretativa, evaluada positivamente en razón de la calidad de sus 


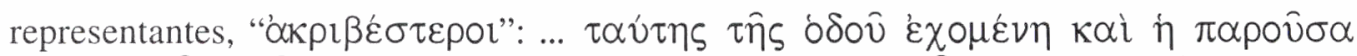

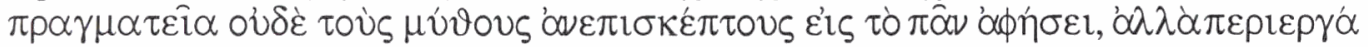

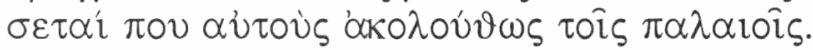

En razón de su índole científico-pedagógica, el discurso postula una doble destinación: por un lado, el receptor de los consejos y enseñanzas, el joven estudiante; por otro, el crítico, el que puede no estar de acuerdo con las propuestas de análisis (el segundo párrafo proporciona abundante información al respecto).

4.2.- Lo señalado precedentemente sobre el cuadro de referencias y su función organizadora, permite afirmar que el Proemio compromete a los siguientes actantes discursivos:

1) el emisor, que procura analizar y enseñar;

2) el destinatario, al que el emisor intenta instruir;

3) el crítico de su análisis, al que el emisor intenta persuadir;

4) los anteriores críticos y estudiosos de Homero, a los que el emisor utiliza como punto de referencia para su propia interpretación;

5) los beneficiarios de la obra homérica, nombrados por el emisor en razón de los valores y virtudes enumerados;

6) Homero y su poesía como centro de estudio del emisor; lo menciona y designa señaladamente.

4.3.- Pero Eustacio no sólo postula las mencionadas figuras, sino que, para poder traducir sus objetivos en actos interpretativos propios de una labor exegética, proporciona además información sobre las condiciones de producción ${ }^{12}$ que han de posibilitar a esos actantes del presente enunciado la inserción en un determinado marco enunciativo: a cada secuencia global del discurso ${ }^{13}$ corresponde una frase que tiene (invariablemente) como Sujeto una forma $\tau l \zeta$, un Objeto que hace referencia precisamente al tema de estudio en cuestión (Homero/la poesía homérica), y un verbo con modalidad hipotética, según las siguientes posibilidades ${ }^{14}$ :

a) ... E้l $\tau 1 \zeta \ldots$... (la más frecuente estructura sintáctica):

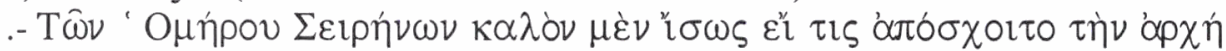

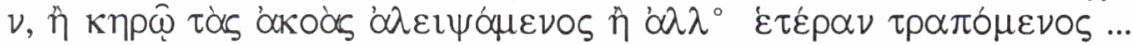

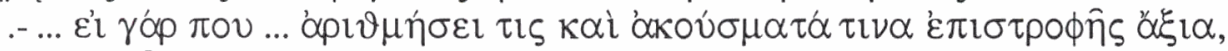

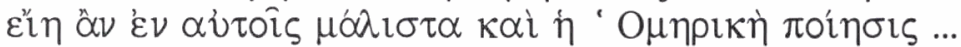

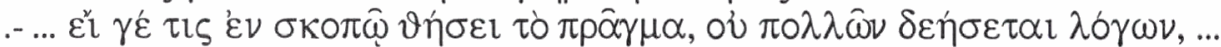

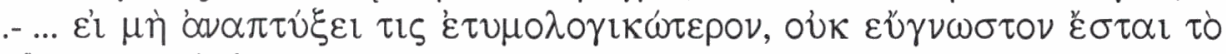

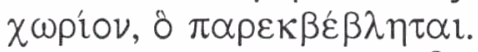

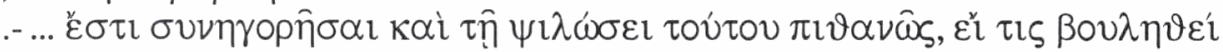
$\eta$.

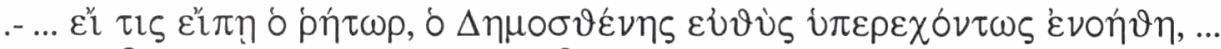

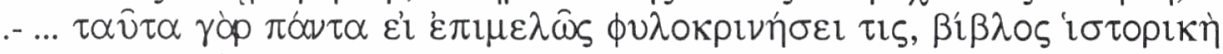

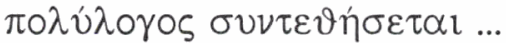

b) $\tau \iota \varsigma+$ ع $\chi \varepsilon \iota v$ (matiz modal) + infinitivo:

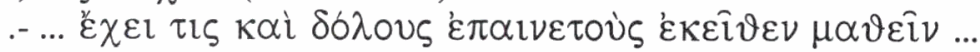

c) $\tau \iota \varsigma$ en cláusula (apositiva) con optativo $+\alpha^{\prime \prime} \nu$ :

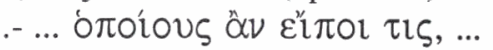

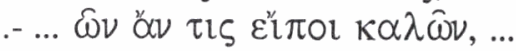


d) $\tau \iota \varsigma$ en cláusula (independiente) con subjuntivo + $\alpha$ :

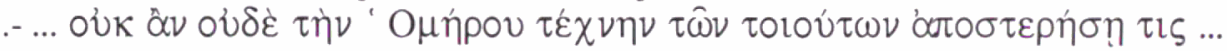

e) $\tau \imath \varsigma$ + participio con matiz condicional:

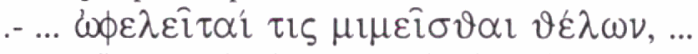

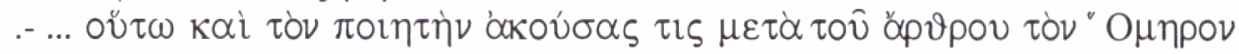

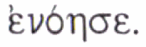

Las citadas expresiones hipotéticas hacen referencia a actividades tales como: apartarse de los poemas en un principio, o si no, ir a través de ellos; enumerar grandes obras e incluir la Ilíada y la Odisea; poder hablar de las cualidades de la poesía homérica; no deber privar a la Ilíada y la Odisea de sus correspondientes virtudes; poder nombrar sabios que se nutren de esta poesía; poder aprender métodos, proponerse esta empresa de un modo adecuado, desear imitar la Ilíada, dar etimologías y preferir algunas en particular; nombrar un determinado género literario y pensar en su más grande exponente.

Esta expresión de las condiciones de producción, en el alcance y variedad de todas sus posibilidades, se caracteriza por destacar la invariabilidad de sus elementos componentes:

1) el Sujeto siempre presenta la misma forma lingüística que hace referencia a un agente indefinido ${ }^{15}$;

2) el Objeto remite en forma permanente al campo referencial "Homero/poesía épica";

3) las expresiones verbales hipotéticas especifican el conjunto de situaciones en las que puede satisfacerse la producción del análisis de Eustacio ${ }^{16}$. El condicional hipotético ei (y de un modo similar las estructuras modales ${ }^{17}$ ), es definido como un operador importante específicamente para las generalizaciones, y, por ende, para la formulación de leyes, principios y reglas ${ }^{18}$.

Con esta forma lingüística, Eustacio puede incluir en (el alcance de) sus generalizaciones a todos aquellos Sujetos alternativos capaces de aceptar el papel hipotético del emisor ${ }^{19}$. Este participante indefinido (tanto Eustacio, como su destinatario, como cualquiera que se ubicare en esta línea de investigación, aún nosotros), pronuncia de modo universal el posible alcance de una situación generalizada: la situación del estudioso de los poemas homéricos.

\section{Conclusión}

Eustacio organiza los cuatro párrafos del Proemio en relación con tres áreas de investigación: fundamentación teórica, objetivos, metodología. Una vía para interpretar dicha organización consiste en delimitar el sistema de referencias personales y definirlo en su vinculación con los modos generales de estructuración del texto. Se jerarquiza la forma tis + modalidad hipotética, como un medio instrumental idóneo para pasar de lo personal, particular y definido (que caracteriza al sistema organizativo de referencias), al plano de lo impersonal, general e indefinido (propio de las generalizaciones formuladas). De este modo Eustacio puede anticipar las condiciones posibles de producción sobre las que su discurso exegético ha de articularse. El valor esencial del Proemio consiste en que, por este medio y aún en nuestros días, Eustacio sigue comprometiendo a los estudiosos de Homero como verdaderos protagonistas del análisis. 


\section{Notas}

1 - Para el presente trabajo se ha utilizado la edición de Leipzig (Stallbaum ed. 18221830), reimpresa en Olms-Hildesheim 1960 (7 vols.). Aún no se cuenta con la edición de Leiden Brill a los comentarios iliádicos (Van der Valk 1971), en 3 vols., material que ha sido solicitado al extranjero.

2 - Cuenta con material procedente de los escritos de los cuatro hombres (en los escolios iliádicos contenidos en el manuscrito Venetus $454 \mathrm{~A}$, del siglo X, se mencionan cuatro estudiosos -Aristonico, Dídimo, Herodiano y Nicanor, contemporáneos de Augusto los dos primeros y de Marco Aurelio los últimos-, responsables de transmitir la investigación alejandrina a la época posterior), a través de comentarios posteriores.

3 - Cf., por ejemplo, Gertrud Lindberg (Lindberg 1985 p 125-140) y su tesis (Lindberg 1977).

4 - El presente trabajo jerarquiza en el discurso su realización formal. Cf. Émile Benveniste (Benveniste 1987 p. 82 sqq.) para la fundamentación metodológica teóricamente idónea para el análisis.

5 - Cf., por ejemplo, Zeno Tarsensis, Stoicus I, 15.

6 - Ha sido motivo de otro trabajo (cf. Liñares 1994).

7 - Para el estudio de la referencia, se ha consultado las siguientes propuestas teóricas: Kerbrat-Orecchioni 1986 p. 46 sqq.; van Dijk 1984 -orig. 1977- p. 49 sqq.; Searle 1986 -orig. 1969- p. 33 sqq. y 130 sqq.; Halliday \& Hasan 1976 p. 31 sqq.

8 - Se seleccionan estos elementos, en virtud de su pertenencia al corpus analizado.

9 - Se jerarquiza asimismo el uso reiterado de $\check{\iota} \nu \alpha$ con valor "consecutivo", para la articulación de expresiones conclusivas (cf. Sophocles 1887).

10- Para este empleo de la 1ra. persona del plural, cf. Kerbrat-Orecchioni 1986 p. 54 n. 10 y p. 82 n. 58.

11-Kerbrat-Orecchioni 1986 p. 196 analiza este recurso como marca de "objetividad".

12- En el presente trabajo se define al discurso como una organización trasoracional articulada sobre condiciones de producción (cf. Maingueneau 1980 -orig. 1976- p. 25); esta definición se apoya en las teorías de la enunciación, jerarquizando al emisor, al receptor, y a la variación de las situaciones comunicativas.

13- Van Dijk 1984 -orig. 1977- p. 195 sqq. define estas unidades globales como macroestructuras del discurso.

14- Para los conceptos básicos de lógica modal y su semántica, cf. van Dijk 1984 -orig. 1977 - p. 60 sqq.

15- Beatriz Lavandera (Lavandera 1984 p. 101 sqq.) proporciona pautas teóricas y metodológicas útiles para el estudio del pronombre indefinido.

16- Para el estudio de los nexos condicionales hipotéticos, cf. van Dijk 1984 -orig. 1977-p. 127 sqq.

17- Para el status modal del condicional hipotético, cf. van Dijk 1984 -orig. 1977- p.308309.

18- Cf. van Dijk 1984 -orig. 1977- p. 128.

19- Algunas cláusulas con (E`) $\tau \iota \varsigma$... resultan desambiguadas: el contexto proporciona información para la personalización, ya sea especificando datos del Sujeto ( $\tau \iota \varsigma \tau \hat{\omega} \nu \pi \alpha$ 
$\lambda \alpha \iota \sigma o \phi \omega \hat{\nu}$...), ya sea conteniendo en la misma frase la presencia -indirecta- de Eustacio

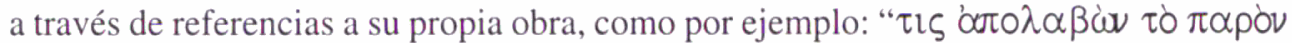

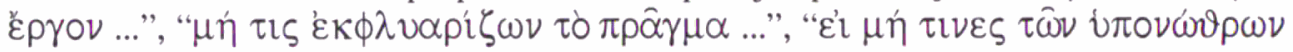
$\mu$

\section{Referencias bibliográficas}

BENVENISTE, Émile, Problemas de lingüística general. Traducción de Juan Almela. México: Siglo XXI, 7a. ed., 1987, vol. II (orig. Paris, 1974)

HALLIDAY, M. A. K. \& HASAN, Ruqaiya, Cohesion in English. London: Longman, 1976.

KERBRAT-ORECCHIONI, Catherine, La enunciación. De la subjetividad en el lenguaje. Traducción de Gladys Anfora y Emma Gregores. Buenos Aires: Hachette, 1986 (orig.: Paris ?).

KIRK, Geoffrey S., Los poemas de Homero. Traducción de Eduardo J. Prieto y Ramón Alcalde. Buenos Aires: Paidós, 1968 (orig. London, 1962).

LAVANDERA, Beatriz. Variación y significado. Buenos Aires: Hachette, 1984.

LINDBERG, Gertrud. Eustathius on Homer: Some of his approaches to the text, exemplified from his Comments on the first book of the Iliad. Eranos, Uppsala, v. 83, p. 125-140, 1985.

Studies in Hermogenes and Eustathius. Lund: Lindell \& Co., 1977.

LIÑARES, Lucía. Homero en Eustacio: trayectoria hacia una definición del poieîn. Homenaje a Aída Barbagelata (In Memoriam). Buenos Aires: Actualidad Producciones, 1994, vol. I, p. 71-81.

MAINGUENEAU, Dominique. Introducción a los métodos de análisis del discurso. Traducción de Lucila Castro. Buenos Aires: Hachette, 1980 (orig. Paris, 1976).

SEARLE, John. Actos de habla. Traducción de Luis M. Valdés Villanueva. Madrid: Cátedra, 1986 (orig. London, 1969).

SOPHOCLES, E. Greek Lexicon of the Roman and Byzantine periods (from B.C. 146 to A.D. 1100). New York: Charles Scribner's Sons, 1887.

STALlBAUM (ed.). Eustathii Commentarii ad Homeri Iliadem et Odysseam. Leipzig: Weigel, 1827-1830 (7 vols.), reimpresa en Olms: Hildesheim, 1960.

VALK, Marchinus van der (Ed.). Eustathii Commentarii ad Homeri lliadem. Leiden: Brill, 1971 (3 vols.). 
VAN DIJK, Teun, Texto y contexto. Traducción de Juan Domingo Moyano. Madrid: Cátedra, 1984 (orig. London, 1977). Classica, São Paulo, 11/12, p. 321-328, 1998/1999.

LIÑHARES, Lucia Adriana. Eustathe et le Préface à ses Commentaires à l'Illiade. Classica, São Paulo, 11/12, p. 321-328, 1998/1999.

RÉSUMÉ: Dans le Préface à ses Commentaires à l'lliade, Eustathe attire l'attention sur les valeurs essentielles de la poésie homérique, et même un certain nombre de problèmes étudiés par la critique. Le présent travail se propose d'arriver à établir quelques principes qui permettent de comprendre l'exégèse d'Eustathe, par l'examen des références trouvées dans le texte.

MOTS-CLÉS: Discours; référence; Iliade; personne; Eustathe; scolies et commentaires; critique. 